\title{
Unusual sites of Aggregata octopiana infection in octopus cultured in floating cages
}

\author{
S. Pascual *, A.F. González, A. Guerra \\ Instituto de Investigaciones Marinas, ECOBIOMAR, Eduardo Cabello 6, 36208 Vigo, \\ Spain
}

\begin{abstract}
This paper deals with the unusual finding of sporogonial stages of Aggregata octopiana in the gills and mantle musculature of cultured octopuses being reared in NW Spain. A histopathological evaluation revealed a limited infection and an acute host response. The origin of this unusual infection site is discussed.
\end{abstract}

Keywords: Aggregata; Reared octopus; Histopathology

* Corresponding author. Tel.: +34 986 231930; fax: +34 986292762.

E-mail address: spascual@iim.csic.es (S. Pascual).

\section{Introduction}

Octopods represent a major protein resource in most seafood consumer countries (FAO, 2002). The best known species, the common octopus Octopus vulgaris Cuvier, 1798, is the most important commercial species and is a serious candidate to be a new aquaculture product (García and Aguado, 2002; Chapela et al., in press).

The eimeriorin coccidian Aggregata octopiana (Apicomplexa: Aggregatidae) is known to heavily infect the digestive tract of octopus, cuttlefish and squids (Pascual et al., 1996). This coccidiosis impairs the well-being of cephalopods, believed to cause a malabsorption syndrome (Gestal et al., 2002a) which finally reduces growth and condition of infected populations (Gestal, 2000). Herein, we describe the unusual sites of Aggregata infection in an experimental culture system of octopuses. 
A total of 62 post-recruit $\mathrm{O}$. vulgaris ranging from 1.0 to $2.52 \mathrm{~kg}$ were collected randomly from floating cages located in the Ria of Vigo (NW Spain) (Fig. 1A). At the laboratory, individuals were killed and examined for parasite infection (Fig. 1B). Under the stereomicroscope we noted whitish oocysts in the gills and the mantle musculature of seven heavily infected octopuses. Tissue samples were histologically processed following standard procedures to confirm the infection. The number of sporocysts (expressed as total number and number per gram) was counted in each infected animal after they were isolated and purified from host tissues using Sucrose and Percoll density gradient centrifugation.

\section{Results}

During the observation of gill sections we noted numerous oocysts containing mature sporocysts located in the stalks joining the primary lamellae to the branchial gland, and also within the band of connective tissue joining the dorsal and ventral lamellae (Fig. 1C). Invaded host cells exhibited considerable hypertrophy and the nucleus appeared displaced to one side. Infiltration of hemocytes and phagocytosis of sporogonic stages was seen in most infected areas (Fig. 1D). Histological sections of the inner side of the mantle musculature also revealed the presence of numerous oocysts with mature sporocysts located between muscle fibers (Fig. 1E-F). In the infected areas destruction of the tissue organ architecture was observed with large host tissue areas replaced by parasites. Gamogonial stages were never seen in sections of infected gills and mantle musculature. Neither gamonts nor gametes were present in the gills or musculature of sampled octopus having extra-intestinal sites of infection.

\section{Discussion}

The histopathology associated with the coccidian infection reported is quite similar to the observations of Gestal et al. (2002b) in the target organs of the digestive tract of the common octopus. Extra-intestinal sites of infection (i.e., the covering mesenteries of digestive gland and gonad, gills and mantle musculature) had been reported in heavily infected octopus from the wild (Gestal, 2000). Nevertheless, these unusual sites of 
infection had not been previously reported in cultured animals, likely because the infrapopulation size of the sporocyst number (i.e., the severity of infection) is much lower in cultured octopus than in wild individuals (Gestal, 2000). A feeding pattern of octopus ongrown in floating cages based on thawed fish species from commercial discards may be responsible for this difference. The absence or small number of intermediate hosts (i.e., crustaceans) in the diet of cultured octopus made these animals less vulnerable to infection than octopods in the wild. Thus, heavily infected octopods are likely to be uncommon in floating cages. Nevertheless, in the cultured octopus which presented infected gills and mantle musculature we counted a mean total number over 52000 sporocysts (2568 sporocysts/g) made on fresh preparations of the infected digestive tract. This infection intensity was comparable to that of heavily infected wild animals (Gestal, 2000). Otherwise, the absence of micro- and macrogamonts and gametes in the infected gill and mantle tissues is worthy of notice. This result may be due to a migration of highly invasive oocysts (Poynton et al., 1992). As a whole, the damage to the host caused by the A. octopiana infection in the gills and mantle musculature does not seem to be serious to the health of the individual animal. In fact, based on the observed material it is likely that host defence-responses may well control the number of parasites occurring at these unusual sites of infection.

Acknowledgements

Authors are grateful to Alberte Chapela for providing the octopus, Jose Antonio Durán for technical assistance and Manuel E. Garci for providing photographs of floating cages.

\section{References}

Chapela, A., González, A.F., Guerra, A., Dawe, E.G., in press. Growth of common octopus (Octopus vulgaris) in cages suspended from rafts. Sci. Mar.

FAO, 2002. Yearbook. Fishery Statistics, vol. 94/1. FAO, Rome.

García, B., Aguado, F., 2002. Influence of diet on ongrowing and nutrient utilization in the common octopus (Octopus vulgaris). Aquaculture 211, 171-182.

Gestal, C., 2000. Epidemiología y patología de las coccidiosis en cefalópodos. PhD thesis, Universidad de Vigo. 157 pp. 
Gestal, C., Páez de la Cadena, M., Pascual, S., 2002a. Malabsorption syndrome observed in the common octopus Octopus vulgaris infected by Aggregata octopiana (Protista: Apicomplexa). Dis. Aquat. Org. 51, 61-65.

Gestal, C., Abollo, E., Pascual, S., 2002b. Observations on associated histopathology with Aggregata octopiana infection (Protista: Apicomplexa) in Octopus vulgaris. Dis. Aquat. Org. 50, 45-49.

Pascual, S., Gestal, C., Estévez, J., Rodríguez, H., Soto, M., Abollo, E., Arias, C., 1996. Parasites in commercially-exploited cephalopods (Mollusca Cephalopoda) in Spain: an update perspective. Aquaculture 142, 1-10.

Poynton, S., Reimschuessel, R., Stoskopf, K., 1992. Aggregata dobelli N. Sp. and Aggregata millerorum N. Sp. (Apicomplexa: Aggregatidae) from two species of Octopus (Mollusca: Octopodidae) from the Eastern North Pacific Ocean. J. Protozool. 39 (1), 248-256. 
Fig. 1. A: Photograph showing the common octopus in cages suspended from rafts in an experimental growing system. B: Photograph showing an octopus with a heavily infected condition. Note the large number of oocysts (arrows) infecting the different organs. C: Histological section of an infected gill showing a fully developed oocyst (O) within a hypertrophied host cell of a frontal primary lamella (Pl). Arrow shows the cellular nucleus $(\mathrm{N})$ displaced to one side of the cell. D: As in C showing infiltration by haemocytes $(\mathrm{H})$. E: Histological section of a computer manipulated digitised image showing an oocyst $(\mathrm{O})$ embedded in the mantle musculature $(\mathrm{M})$. F: Oocysts (O) replacing large areas of mantle musculature (M). 

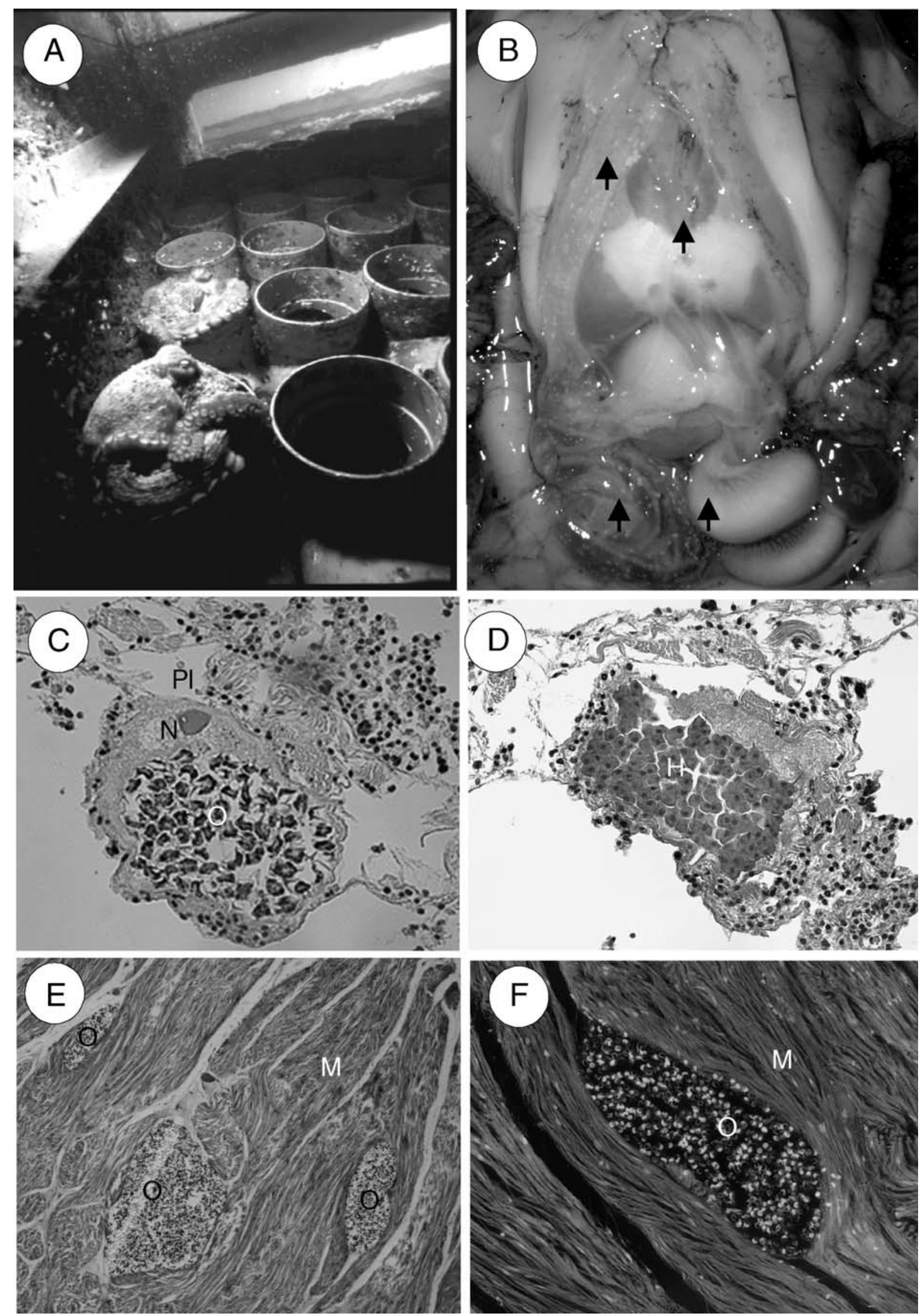